\title{
The lived experience of women with faecal incontinence after childbirth: a thematic synthesis
}

\author{
Jennifer MacLellan, Simona Fourie \\ Citation
}

MacLellan J, Fourie S (2019) The lived experience of women with faecal incontinence after childbirth: a thematic synthesis. Primary Health Care. doi: 10.7748/phc.2019.e1541

\section{Peer review}

This article has been subject to external double-blind review and has been checked for plagiarism using automated software

\author{
Correspondence \\ jennifer.maclellan@ndm.ox.ac.uk
}

\section{Conflict of interest}

None declared

\section{Acknowledgements}

We would like to acknowledge the support and encouragement of Professor Alison Simmons in developing this project

Availability of data and material

The datasets analysed are available from the corresponding author on reasonable request

Accepted

31 December 2018

Published online

\begin{abstract}
The prevalence of faecal incontinence in the general population is estimated to be between $11-15 \%$, with a subgroup of younger women experiencing a higher prevalence linked to childbirth injury. Such injury is estimated to occur in up to $16 \%$ of vaginal births, equating to potentially 80,000 affected women a year who experience a variety of symptoms from perineal pain, urgency, incontinence and psychological morbidity. The perspective of women living with faecal incontinence as a result of childbirth injury is largely missing from the data. This project aimed to address the gap by pulling together women's perspectives through a thematic synthesis.

Thematic synthesis of qualitative research was used to direct this project. A database search of CINAHL, PubMed and the British Nursing Index retrieved 434 records. After review four records were included in the synthesis.

From the data three categories were synthesised: experiencing a compromised identity, living with secrets and feeling isolated. These categories were contained in an overarching theme of invisibility as a woman in the mother/child dyad.

Postnatal faecal incontinence is debilitating and often hidden due to shame, lack of information and support. This synthesis suggests women with postnatal faecal incontinence have similar lived experiences to those with faecal incontinence of different aetiology. The unique difference is the sense of invisibility expressed by the participants of their identity as a woman due to an enduring focus by others on the child's health and their function as a mother.
\end{abstract}

\section{Author details}

Jennifer MacLellan, senior research nurse, Nuffield Department of Medicine, University of Oxford, Oxford, England; Simona Fourie, research nurse manager, Nuffield Department of Medicine, University of Oxford, Oxford, England

\section{Keywords}

childbirth, continence, diarrhoea, faecal incontinence, qualitative research, research

\section{Implications for practice}

- Postnatal faecal incontinence is debilitating and often hidden due to shame, lack of information and support 
- Women with postnatal faecal incontinence may experience a sense of invisibility of their identity as a woman because of an enduring focus by others on the child's health and their function as a mother

- The topic of faecal incontinence should be normalised by healthcare professionals and affected women

\section{Introduction}

The prevalence of faecal incontinence in the general population is estimated to be between $11-15 \%$, although this figure may be inaccurate as embarrassment can prevent people from reporting and seeking help (Macmillan et al 2004 [Q old ref, still valid?], Keogh and Burke 2017, Dibley et al 2018). Living with incontinence has been described as 'complicated' and unpredictable, stimulating shame, secrecy and experiences of stigma (IMPRESS Network 2016, Keogh and Burke 2017, Dibley et al 2018). However, emotional control, social support and mastery over the underlying disease have been linked to the reduction of stigma. The causes of faecal incontinence are attributed to a combination of factors and varying pathophysiology with a rising incidence with advancing age. However, there is a subgroup of younger women with a higher prevalence of faecal incontinence that has been linked to childbirth injury (Ahmad et al 2010).

Obstetric anal sphincter injuries (OASIs) are reported to occur in $0.4-16 \%$ of vaginal births (Andrews et al 2006 [Q old ref, still valid?], Guzmán Rojas et al 2013). With more than 500,000 vaginal births in the UK each year, this equates to potentially 2,00080,000 women [Q refs Andrews et al 2006 [Q old ref, still valid?], Guzmán Rojas et al 2013?]. Most research on this topic has been quantitative in nature exploring prevalence (Gurol-Urganci et al 2013), severity and quality of life using standardised scales (Hayes et al 2007 [Q old ref, still valid?], Tucker et al 2013). As a result, a significant body of literature has accumulated recording the consequences of such injury as perineal pain, faecal urgency, incontinence and psychological morbidity. The lived experiences of women with OASIs are missing from the debate, which led the authors to conduct a thematic synthesis of the body of qualitative data.

\section{Method}

A comprehensive literature search was conducted in March 2018 using the bibliographic databases CINAHL, PubMed and the British Nursing Index. The authors also searched the reference lists of related articles, reports and review articles. Searches were restricted by neither date nor language. The search terms used were 'faecal incontinence after childbirth, qualitative'. The authors screened the title and abstract of the records for inclusion. Records were excluded if they were obviously unrelated to the topic, for example, methods of diagnosing faecal incontinence or reports on obstetric fistula. The remaining records were assessed for inclusion based on a reading of the full text with study quality graded using the Critical Appraisal Skills Programme (2018) checklist for qualitative research. All records were included if they reported the lived experience of women with faecal incontinence after childbirth. The study selection is summarised in the Preferred Reporting Items for Systematic Reviews and Meta-Analyses flow diagram (Moher et al 2009) (Figure 1). [Q please answer queries on Figure 1? NB I have inserted Moher et al 2009 ref as suggested on PRISMA website: http://www.prisma-statement.org/PRISMAStatement/CitingAndUsingPRISMA.aspx]

\section{Figure 1. Preferred Reporting Items for Systematic Reviews and Meta-Analyses flow diagram for the lived experience of women with faecal incontinence after childbirth: a thematic synthesis}

Thematic synthesis of qualitative research as described by Thomas and Harden (2008) was used to direct this project. JM and SF read the records independently and summarised the key constructs on an Excel sheet to facilitate the cross-comparison process of the synthesis. Data were coded after reading the full texts. Codes were assigned to participants' identified concerns and worries (Aveyard et al 2016). The initial agreement level between JM and SF during coding was $85 \%$. From these codes, descriptive themes were constructed. Synthesis of commonalities and contradictions across records brought fresh interpretation to the data with the emergence of analytical themes. Thematic synthesis is influenced by the perspective of the researchers as they inductively create higher order constructs from the author-identified themes of the included records [Q can you express this more simply for a practitioner audience?]. This discrepancy prompted extensive discussion and refinement of coding and theme-naming decisions before $100 \%$ agreement was reached.

\section{Findings}

The three databases yielded 431 records. This was supplemented by reference searching to reveal an additional three records to total 434 records for review. On full-text analysis four studies were included in the synthesis. The sample size was 50 women between the ages of 19-50. All studies were primary research published between 2009 and 2016. Table 1 summarises the four studies. 
Table 1. Summary of included studies and principal constructs

\begin{tabular}{|c|c|c|c|c|c|c|}
\hline Study & Reference & Country & Participants & Method & $\begin{array}{l}\text { CASP } \\
\text { checklist }\end{array}$ & Themes \\
\hline 1 & $\begin{array}{l}\text { Keighley et al } \\
(2016)\end{array}$ & UK & 30 & $\begin{array}{l}\text { Interviews and } \\
\text { focus group }\end{array}$ & $\sqrt{ }$ & $\begin{array}{l}\text { Embarrassment, unclean, mutilated, } \\
\text { grief and anxiety, hiding condition, } \\
\text { compromised in roles, abandoned/let } \\
\text { down }\end{array}$ \\
\hline 2 & $\begin{array}{l}\text { Priddis } \\
\text { (2015) }\end{array}$ & Australia & 1 & Autoethnography & $\sqrt{ }$ & $\begin{array}{l}\text { Let down/lack of support, leaking } \\
\text { body, developing strategies, } \\
\text { limitations, overwhelmed, learning to } \\
\text { survive, disembodiment, } \\
\text { dysfunctional/compromised }\end{array}$ \\
\hline 3 & $\begin{array}{l}\text { Rasmussen } \\
\text { and } \\
\text { Ringsberg } \\
\text { (2010) }\end{array}$ & Denmark & 9 & Interviews & $\sqrt{ }$ & $\begin{array}{l}\text { Altered lifestyle, loneliness, loss of } \\
\text { control, insufficiency, fight to be like } \\
\text { others, stigma, need for confirmation } \\
\text { of identity }\end{array}$ \\
\hline 4 & $\begin{array}{l}\text { Priddis et al } \\
(2014)\end{array}$ & Australia & 12 & Interviews & $\sqrt{ }$ & $\begin{array}{l}\text { Abandoned mother, fractured } \\
\text { fairytale, a completely different } \\
\text { normal, incorporating coping } \\
\text { strategies, broken body, changes in } \\
\text { self, anxiety over unpredictable body, } \\
\text { kept silent }\end{array}$ \\
\hline
\end{tabular}

\section{CASP=Critical Appraisal Skills Programme (2018)}

The findings from the literature were synthesised into three categories:

Experiencing a compromised identity.

Living with secrets.

Feeling isolated.

These categories were contained within an overarching theme of invisibility as a woman in the mother/child dyad (MacLellan and

Fourie 2018) [Q please see ref query?].

\section{Experiencing a compromised identity}

Across the included studies the experience of loss of control over the body, perceived as leaking and damaged, could lead to a sense of failure in one's identity as a mother and as a woman:

'I feel a failure' (Keighley et al 2016).

'I do not feel attractive; it strips away your femininity' (Keighley et al 2016).

The damaged body was seen as having let the woman down, compromising what she expected of her 'self':

'... every time it happened I was just like - oh this is filthy, I'm in my twenties and I can't control myself' (Priddis et al 2014).

Faecal incontinence had a significant effect on women's intimate and wider social relations:

'...eighteen months down the track and it's very rare that we can achieve intercourse...so it certainly has impacted on our relationship' (Priddis et al 2014).

'...wanting to finish [sex] asap and then just I have to go the toilet quickly' (Priddis et al 2014).

\section{Living with secrets}

Our inductive interpretation concluded this compromised identity to require learning to live with the secret of incontinence. Living with a secret required the adoption of survival strategies such as not going out of the house with the new baby; taking sanitary towels, wipes and clean underwear wherever the woman went; changing one's job; or taking medication since being constipated was considered easier to manage (Priddis et al 2014). These strategies supported life under a different normal, enabling women to keep up a façade:

'I prefer to keep it a secret' (Keighley et al 2016).

This façade even extended to their own witness of their incontinence:

'I throw out my pants every time. It becomes very expensive when it happens. But I do it' (Rasmussen and Ringsberg 2010).

\section{Feeling isolated}

The containment of experience by the women living with a secret was further challenged by the perception of stigma from family, friends, health professionals and self. This appeared to constrain potential disclosure and the opportunity for support:

'...I thought it was disgusting so I didn’t want anybody else to judge me for that...' (Priddis 2015). 
These feelings were compounded by a lack of information from health professionals and online sources in the antenatal period about the potential of perineal injury and its consequences:

'Nobody warned me about this' (Keighley et al 2016).

'I wasn't given any numbers or information or anything' (Priddis 2015).

However, when support was sought the response from the healthcare professional was not always felt to be satisfactory:

'Well, haven't you got a leaflet? And I told her, 'Yes I have got a leaflet but maybe I need to talk about it' but they did not understand me' (Rasmussen and Ringsberg 2010).

A combination of self-stigma and the response of healthcare professionals often led to a profound sense of loneliness:

'There was no one I could talk to' (Keighley et al 2016).

\section{Discussion}

Our overarching theme was becoming invisible as a woman in the mother/child dyad.

There was a sense that during the postpartum period the healthcare professional's focus was on the health of the baby and the woman's role as the caregiver. This reductionist approach can be perceived as negating the identity of woman and instead emphasising the mother and child components of the relationship. Consequently, this focus was in opposition to concern for the woman's independent experience of her role transition to mother and the changes in her body after childbirth, with an absence of emphasis on the need to care for herself through the postnatal time. The health professional focus from this synthesis has been reported to revolve around feeding, mental health as it affects bonding and care function, and contraception. However, in the postnatal period, the woman's identity has already been challenged by her transition to the role of mother. To have the cumulative challenge of a damaged and leaking body is a significant assault on her self-concept and her coping skills. Connecting with the self can become increasingly challenging in this context as it can be hidden by the self-stigma and perceived stigma of others. If there is an inability to affect the broken image the woman may hold of herself, her lack of agency can erode confidence and her way of being. It can reduce disclosure of the presence of faecal incontinence and potentially lead to negative coping strategies described under the theme of living with secrets. This can result in self-induced isolation and exacerbation of the felt sense of social invisibility, as described in our overarching theme.

The findings of this synthesis suggest a clear need to normalise the topic of incontinence among health professionals and affected women, as many participants expressed health professionals' lack of engagement with the topic. However, research has shown that women do disclose their experiences if they are approached sensitively in a face-to-face interview (Gray et al 2018) [Q please see ref query?]. The work of Gray et al (2018) showed that it is possible to broach the topic, as shown in the following example:

'It's normal to take a bit of time for the pelvic floor to recover after the stress of pregnancy and birth and some women can experience episodes of urine or stool leak. This should be getting better by now. If it is not, there is targeted support we can help you with. Are you experiencing any urine or stool leak, for example, when you lift your baby or when you are dashing to the toilet?'

As the Whooley et al (1997) [Q seminal ref?] screening questions for depression have become embedded and accepted in practice, the stigma of mental health discussion among maternity professionals and service users has been challenged. In the same way, concerted effort can confront the stigma of faecal incontinence, opening the discussion to focus on the experience of the woman in the triad [Q dyad?] of the mother/child and offer support.

\section{Limitations}

The principal limitations of this synthesis were its reliance on the authors' interpretation of the included records, their selection of evidence and presentation of findings rather than working directly with the narratives of participants.

\section{Conclusion}

This synthesis highlights the devastating consequences of faecal incontinence after childbirth injury. Postnatal faecal incontinence is debilitating and often hidden due to shame, lack of information and support. This synthesis suggests women with postnatal faecal incontinence have similar lived experiences to those with faecal incontinence of different aetiology. The unique difference is the sense of invisibility expressed by the participants of their identity as a woman due to an enduring focus by others on the child's health and their function as a mother. 
A recommended service level response to this phenomenon could be the provision of a link to pelvic floor services through an immediate referral from the attending midwife. The National Institute for Health and Care Excellence (2006) guideline on postnatal care recommends that between six and eight weeks after birth, the coordinating healthcare professional should ensure that the woman's physical, emotional and social well-being is reviewed. This review could be used to encourage women to disclose their experiences and receive valuable and timely support. Increasing screening for the presence of faecal incontinence during routine childhood immunisation time points could offer an alternative opportunity for detection and support.

\section{[Julie Related PHC articles}

https://journals.rcni.com/primary-health-care/managing-pregnancyrelated-pelvic-floor-dysfunction-phc.25.1.24.e913

https://journals.rcni.com/primary-health-care/cpd/improving-outcomes-for-patients-with-irritable-bowel-syndrome-in-primary-carewith-specific-focus-on-diet-phc.2018.e1375/full

https://journals.rcni.com/primary-health-care/management-of-lower-bowel-dysfunction-phc2013.06.23.5.27.e749]

\section{References}

Ahmad M, McCallum I, Mercer-Jones M (2010) Management of faecal incontinence in adults. BMJ. 340, c2964.

Andrews V, Sultan A, Thakar R et al (2006) Occult anal sphincter injuries-myth or reality? BJOG. 113, 2, 195-200.

Aveyard H, Payne S, Preston N (2016) A Post-graduate's Guide to Doing a Literature Review in Health and Social Care. Open University Press, Maidenhead.

Critical Appraisal Skills Programme (2018) CASP Checklist: 10 Questions to Help you Make Sense of a Qualitative Research. https://casp-uk.net/wpcontent/uploads/2018/01/CASP-Qualitative-Checklist-2018.pdf (Last accessed: 12 April 2019.)

Dibley L, Norton C, Whitehead E (2018) The experience of stigma in inflammatory bowel disease: an interpretive (hermeneutic) phenomenological study. Journal of Advanced Nursing. 74, 4, 838-851.

Gray T, Vickers H, Jha S et al (2018) A systematic review of non-invasive modalities which enable assessment and access to care for women with faecal incontinence following childbirth. Abstract 24, First Pelvic Floor Summit, Telford, 18-20 April. [Q can you provide a weblink for the abstract or did it appear in unpublished proceedings?]

Gurol-Urganci I, Cromwell D, Edozien L et al (2013) Third- and fourth-degree perineal tears among primiparous women in England between 2000 and 2012 : time trends and risk factors. BJOG. 120, 12, 1516-1525.

Guzmán Rojas R, Shek K, Langer S et al (2013) Prevalence of anal sphincter injury in primiparous women. Ultrasound in Obstetrics \& Gynecology. 42,4 , $461-466$.

Hayes J, Shatari T, Toozs-Hobson P et al (2007) Early results of immediate repair of obstetric third-degree tears: $65 \%$ are completely asymptomatic despite persistent sphincter defects in 61\%. Colorectal Disease. 9, 4, 332-336.

IMPRESS Network (2016) Patient Perspective. www.impress-network.com/patient-perspective (Last accessed: 12 April 2019.)

Keighley M, Perston Y, Bradshaw E et al (2016) The social, psychological, emotional morbidity and adjustment techniques for women with anal incontinence following obstetric anal sphincter injury: use of a word picture to identify a hidden syndrome. BMC Pregnancy Childbirth. 16, 1, 275.

Keogh A, Burke M (2017) Faecal incontinence, anxiety and depression in inflammatory bowel disease. Gastrointestinal Nursing. 15, 4, 18-27.

MacLellan J, Fourie S (2018) Lived experience of women with faecal incontinence following childbirth. Abstract 25, First Pelvic Floor Summit, Telford, 18-20 April. [Q can you provide a weblink for the abstract or did it appear in unpublished proceedings?]

Macmillan A, Merrie A, Marshall R et al (2004) The prevalence of fecal incontinence in community-dwelling adults: a systematic review of the literature. Diseases of the Colon and Rectum. 47, 8, 1341-1349.

Moher D, Liberati A, Tetzlaff J et al (2009) Preferred reporting items for systematic reviews and meta-analyses: the PRISMA statement. PLoS Medicine. 6, 7, e1000097. National Institute for Health and Care Excellence (2006) Postnatal Care up to 8 Weeks after Birth. Clinical guideline 37. NICE, London.

Priddis $\mathrm{H}$ (2015) Autoethnography and severe perineal trauma: an unexpected journey from disembodiment to embodiment. BMC Women's Health. 15 , 88.

Priddis H, Schmied V, Dahlen H (2014) Women's experiences following severe perineal trauma: a qualitative study. BMC Women's Health. 14, 1, 32.

Rasmussen J, Ringsberg K (2010) Being involved in an everlasting fight: a life with postnatal faecal incontinence. A qualitative study. Scandinavian Journal of Caring Sciences. 24, 1, 108-115. 
Thomas J, Harden A (2008) Methods for the thematic synthesis of qualitative research in systematic reviews. BMC Medical Research Methodology. 8, 45.

Tucker J, Wilson A, Clifton V (2013) Women's experience of anal incontinence following a history of obstetric anal sphincter injury: a literature review. International Journal of Evidence-Based Healthcare. 11, 3, 181-186.

Whooley M, Avins A, Miranda J et al (1997) Case-finding instruments for depression. Two questions are as good as many. Journal of General Internal Medicine. 12, 7 , $439-445$. 